\section{Sensory Comparison of Ciders Produced from Machine- and Hand-harvested 'Brown Snout' Specialty Cider Apples Stored at Ambient Conditions in Northwest Washington}

\author{
Travis Robert Alexander ${ }^{1,3}$, Carolyn F. Ross ${ }^{2}$, Emily A. Walsh ${ }^{2}$, \\ and Carol A. Miles ${ }^{1}$
}

ADDITIONAL INDEX wORDs. labor, shake-and-catch, Malus $\times$ domestica, sensory evaluation, trained panel, electronic tongue

SUMmARY. Machine harvest of 'Brown Snout' specialty cider apple (Malus $\times$ domestica) has been shown to provide yield and juice quality characteristics similar to that of hand harvest. In this 2-year study, the sensory perception (color, aroma, flavor, mouthfeel, taste, and aftertaste) of ciders produced from machine-harvested and hand-harvested fruit that were ambient stored $\left(56^{\circ} \mathrm{F}\right) 0-4$ weeks postharvest were compared using a trained panel and electronic tongue (e-tongue). For nearly all sensory attributes evaluated, the trained panelists scored the 2014 machine-harvested samples higher than the $\mathbf{2 0 1 4}$ hand-harvested samples. Some of the key sensory differences included a darker color, a more astringent and heated mouthfeel, and a more sour taste of the machine-harvested samples than the hand-harvested samples. Trained panelists perceived no differences due to the harvest method among the 2015 samples for any of the sensory attributes evaluated. The e-tongue demonstrated good discrimination (index value $=95$ ) of 2014 samples, but poor discrimination (index value $=-0.5$ ) of 2015 samples, mirroring the year-to-year variation experienced by the trained panelists. Overall, the e-tongue demonstrated a response to metallic and sour that was more associated with the machine-harvested samples and a response to sweet and umami that was more associated with the hand-harvested samples. These results demonstrate that cider made from machine-harvested fruit can have a different sensory profile than cider made from hand-harvested fruit. A consumer tasting panel should be conducted next to provide an indication of market response to the differing sensory profiles, qualifying the impact of harvest method. Results also indicate that ambient storage $\left(56^{\circ} \mathrm{F}\right)$ of fruit up to 4 weeks may not impact cider sensory attributes; however, cider apple growers should avoid ambient storage of machine-harvested fruit given the significant yield losses demonstrated in previous studies. Variation in cider quality due to year of harvest was most likely a result of differences in the hand-harvest technique between the 2 years, specifically more fruit bruising in 2014 than in 2015 , demonstrating the importance of harvesting fully mature fruit with a standard protocol so as to supply a consistent raw material to cider producers. The e-tongue produced variable results compared with trained panelists and more development is needed before it can be incorporated into cider sensory evaluation protocol.

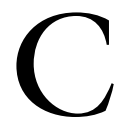
ider as referred to in this study is the product of fermented apple juice that may contain $0.5 \%$ to $8.5 \%$ alcohol by volume

Funding support for this project is gratefully acknowledged from Washington State University Emerging Research Issues Grant \#15-01-02, the Washington State Department of Agriculture Specialty Crop Block Grant K1270, and Washington State project WN00427, Acc. No. 1000194 Saul Phillips and Megan Schumaker are acknowledged for their assistance in optimizing methodology.

${ }^{1}$ Department of Horticulture, Washington State University, 16650 State Route 536, Mount Vernon, WA 98273

${ }^{2}$ School of Food Science, Washington State University, P.O. Box 646376, Pullman, WA 99164

${ }^{3}$ Corresponding author. E-mail: travis.alexander@ wsu.edu.

https://doi.org/10.21273/HORTTECH03909-17
(ABV) (Alcohol and Tobacco Tax and Trade Bureau, 2015). Cider is the fastest growing segment of the U.S. alcohol beverage market; production increased 22 -fold over the last 10 years, from 775,031 gal of cider in 2007 to $17,503,535 \mathrm{gal}$ in 2016 (Alcohol and Tobacco Tax and Trade Bureau, 2017). A major challenge to a sustained growth of the U.S. cider industry is the increasing labor shortages faced by apple growers across the nation (Thilmany, 2001). Cider apples are harvested by hand in the United States, and when labor is unavailable, profits are unrealized from unharvested fruit and their incurred production costs. Since 2011, the Washington State University (WSU) cider program has been evaluating the mechanization of cider apple harvest as a long-term solution to growers' vulnerable dependency on hand labor. Alexander et al. (2016) and Miles and King (2014) have demonstrated the efficacy of mechanically harvesting 'Brown Snout' specialty cider apples with an over-the-row shake-and-catch small fruit harvester in terms of fruit yield and juice quality characteristics (i.e., the raw materials). Mechanical harvest imparted greater bruising to 'Brown Snout' fruit than hand harvest, and this physical damage resulted in significant yield loss postharvest when fruit were not immediately processed or cold-stored. The juice quality characteristics of 'Brown Snout' fruit did not differ because of harvest method when fully mature fruit were stored for 0,2 , or 4 weeks at 32 or $56^{\circ} \mathrm{F}$.

The present study advanced the assessment of mechanical harvest of 'Brown Snout' by evaluating cider quality (i.e., the finished product). Sensory evaluation of cider quality was performed using a trained panel

\begin{tabular}{lllc}
\hline $\begin{array}{l}\text { Units } \\
\text { To convert U.S. to SI, } \\
\text { multiply by }\end{array}$ & U.S. unit & SI unit & $\begin{array}{l}\text { To convert SI to U.S., } \\
\text { multiply by }\end{array}$ \\
\hline 0.05 & drop $(\mathrm{s})$ & $\mathrm{mL}$ & 20.0 \\
29.5735 & $\mathrm{fl} \mathrm{oz}$ & $\mathrm{mL}$ & 0.0338 \\
0.3048 & $\mathrm{ft}$ & $\mathrm{m}$ & 3.2808 \\
3.7854 & $\mathrm{gal}$ & $\mathrm{L}$ & 0.2642 \\
2.54 & inch $(\mathrm{es})$ & $\mathrm{cm}$ & 0.3937 \\
0.4536 & $\mathrm{lb}$ & $\mathrm{kg}$ & 2.2046 \\
28.3495 & $\mathrm{oz}$ & $\mathrm{g}$ & 0.0353 \\
7.4892 & $\mathrm{oz} / \mathrm{gal}$ & $\mathrm{g} \cdot \mathrm{L}^{-1}$ & 0.1335 \\
62.5000 & $\mathrm{oz} / \mathrm{lb}$ & $\mathrm{g} \cdot \mathrm{kg}^{-1}$ & 0.0160 \\
1 & $\mathrm{ppm}$ & $\mathrm{mg} \cdot \mathrm{L}^{-1}$ & 1 \\
0.001 & $\mathrm{ppm}$ & $\mathrm{mL} \cdot \mathrm{L}^{-1}$ & 1000 \\
6.8948 & $\mathrm{psi}$ & $\mathrm{kPa}$ & 0.1450 \\
14.7868 & tablespoon $(\mathrm{s})$ & $\mathrm{g}$ & 0.0676 \\
$\left({ }^{\circ} \mathrm{F}-32\right) \div 1.8$ & ${ }^{\circ} \mathrm{F}$ & ${ }^{\circ} \mathrm{C}$ & $\left({ }^{\circ} \mathrm{C} \times 1.8\right)+32$
\end{tabular}


and an e-tongue. Sensory panels, involving screened individuals trained to describe their sensory experiences using specific terminology and metrics, are often used to guide product development in contrast to consumer tasting panels that are used to test market acceptability (Meilgaard et al., 2006). Sensory panelists' perceptions can provide an indication of ordinary consumer response and can detect minute differences in product characteristics. Sensory panelists can also become fatigued and subject to biases, and the process incurs a large time commitment and accordingly high cost. The e-tongue is a powerful tool that provides for an analytical measurement of taste profiles. E-tongues can be calibrated to consistently provide objective data, contrary to the human brain whose reaction can vary daily in response to biological, emotional, and environmental variables. Furthermore, e-tongues can evaluate samples that are potentially harmful to humans. However, e-tongues lack the streamlined integration of the human sensory system that can combine data from multiple senses to form classifications or judgments.

It was expected that machine harvest of 'Brown Snout' fruit would ultimately provide for a darker colored and less astringent and bitter cider than hand harvest. The physical damage imparted by mechanical harvest results in fruit that is vulnerable to enzymatic oxidation, a process that results in browning and chemical alteration of phenolics, as well as physiochemical interactions that can include binding of phenolics with insoluble solids (e.g., polysaccharides) (Guyot et al., 2008; Lea, 1990; Nicolas et al., 1994; Renard et al., 2001). The size, structure, and stereochemistry of phenolics, predominantly procyanidins in cider, are important as they influence the perception of cider's beverage characteristic astringency and bitterness (Lea and Arnold, 1978). Also, mechanization of harvest could provide for a metallic taste as this response has been associated with food products that are oxidized and have had prolonged contact with metals (deMan, 1999). Experiments have shown machine-harvested grapes (Vitis vinifera) to contain up to six times the content of iron than hand-harvested grapes, levels that can result in a perceived metallic taste (Loubère, 1990). It was also expected that duration of ambient storage of fruit would augment the effect of harvest method as time would allow for a greater extent of oxidation and polymerization of phenolics, especially in fruit damaged during harvest. Variation in sensory perception due to year of harvest was expected as the previous mechanization studies assessing fruit yield and juice quality characteristics demonstrated a significant year effect (Alexander et al., 2016; Miles and King, 2014). Finally, the e-tongue has been shown to complement human evaluations of similar products such as wine, but the need for further optimization would not be surprising as this study is the first to involve cider (Baldwin et al., 2011). Legin et al. (2003) demonstrated the ability of an e-tongue to distinguish red and white wines from different geographical areas as well as vintages, and the ability to predict the scoring of trained panelists with $8 \%$ to $13 \%$ error.

In this 2-year study, fermented juice produced from machine-harvested and hand-harvested 'Brown Snout' that was ambient stored $\left(56{ }^{\circ} \mathrm{F}\right)$ for 0,2 , and 4 weeks postharvest was evaluated using a trained panel and e-tongue. The sensory profiles of the ciders were compared by the harvest method, fruit ambient storage time, and year of harvest, and the complementation of human evaluations by the e-tongue in profiling cider was assessed.

\section{Materials and methods}

Fruit Harvest. This 2-year study had a split-plot design with main plots arranged in a completely randomized design. The main plot factor was the harvest method, with two levels, and the subplot factor was ambient storage time, with three levels. In 2014 and 2015 at WSU Mount Vernon Northwestern Research and Extension Center (NWREC), a trellis planting of 'Brown Snout' specialty cider apple, grafted on 'Malling 9' or 'Malling 27' rootstock, was handharvested by four unskilled agricultural workers and mechanically harvested with an over-the-row small fruit harvester (model OR0012; Littau Harvester, Lynden, WA). Harvest method was randomly applied to eight main plots consisting of an average of nine trellised trees each, providing for four replicates of each of the two harvest methods. In previous studies using the same exact trellis planting (Alexander et al., 2016; Miles and King, 2014), rootstock was shown to be nonsignificant, and so in this study, they were pooled together. The 'Brown Snout' planting was established in 2002 in soil type Skagit silt loam, a fine-silty, mixed, nonacid, mesic Typic Fluvaquent (U.S. Department of Agriculture, 2013). The trees were planted at 16- $\mathrm{ft}$ between-row and 4 - $\mathrm{ft}$ in-row spacing, trained to a three-wire trellis system with the lowest wire $2 \mathrm{ft}$ above the soil surface, and pruned to a maximum height of $6.5 \mathrm{ft}$, all to accommodate the mechanical harvester used in this study. The trees were fertilized, irrigated, and sprayed following recommended regional commercial practices (Moulton and King, 2008; WSU, 2013). Both years of this study, fruit were harvested when fully ripe, 8.5 of 9 starch index value [BC/ Ontario starch index (Blanpied and Silsby, 1992; Chu and Wilson, 2000)], and in the following sequence: preharvest groundfalls were removed from all plots, hand-harvest plots were picked, and machineharvest plots were harvested. With both harvest methods, fruit was collected in polyethylene grape boxes.

On completion of harvest, three filled grape boxes (on average $40 \mathrm{lb} /$ box) were randomly selected from each of the main plots for assessment of three ambient $\left(56^{\circ} \mathrm{F}\right)$ storage treatments. One box was ambient stored for 0 weeks, one box was ambient stored for 2 weeks, and one box was ambient stored for 4 weeks. Storage temperature was measured every 15 min (Hobo U12 4-channel; Onset Computer Corp., Bourne, MA). At the completion of each storage time treatment, the respective boxes were sorted, rotted fruit were discarded, and the remaining fruit milled (MultiMax 30; Zambelli Enotech, Camisano Vicentino, Italy) and pressed (Carezza; Enotecnica Pillan, Camisano Vicentino, Italy). The juice was collected in separate 1-gal polyethylene jugs (ULINE, Pleasant Prairie, WI) and frozen at $5{ }^{\circ} \mathrm{F}$ until they were thawed for fermentation at NWREC.

Juice fermentation. Frozen juice samples were thawed to $68^{\circ} \mathrm{F}$ 
and juice fermented pursuant to a varietal protocol established for this study by a regional cider expert (Zimmerman et al., 2015). The following key steps summarize the varietal cider protocol. As all of the samples were in the desired $\mathrm{pH}$ range of 3.3-3.7 (measured with Orion 3 Star pH meter; Thermo Fisher Scientific, Waltham, MA), malic acid adjustments were not performed. Given an average $\mathrm{pH}$ of 3.7 , sulfite (potassium metabisulfite; Esseco USA, Parsippany, NJ) was added at a dosage of $150 \mathrm{mg} \cdot \mathrm{L}^{-1}$. Yeast (DV-10; Lallemand, Rexdale, Canada) was hydrated (100 g. $\left.\mathrm{kg}^{-1}, 104^{\circ} \mathrm{F}\right)$, allowed to cool to $80{ }^{\circ} \mathrm{F}$ to avoid thermal shock, and added to the $68^{\circ} \mathrm{F}$ juice at a dosage of $0.31 \mathrm{~g} \cdot \mathrm{L}^{-1}$ (all within manufacturer recommendations). Pectinase ( $100 \mathrm{~g} \cdot \mathrm{kg}^{-1}$; KS; Scott Laboratories, Petaluma, CA) was added at a dosage of $0.08 \mathrm{~mL} \cdot \mathrm{L}^{-1}$ and the juice left to sit a few hours to allow for enzyme activity. The treated juice was siphoned off the sediment into l-gal carboys (ULINE) with air locks, leaving at most $1 \%$ observed headspace for initial foam formation, and the carboys were allowed to ferment at $68^{\circ} \mathrm{F}$. When specific gravity (SG) readings dropped by one-third of the initial values, supplemental yeast nutrients (Fermaid K; Scott Laboratories) were added at a dosage of $0.25 \mathrm{~g} \cdot \mathrm{L}^{-1}$. When SG dropped below 1.025 , carboys were topped with extra juice to eliminate any headspace (i.e., contact of oxygen and fermented juice). Fermentation continued at $57^{\circ} \mathrm{F}$ until SG was equal to or less than $1.000, \approx 2.5$ weeks after being topped. After 10 weeks, 0.5 $\mathrm{mg} \cdot \mathrm{L}^{-1}$ copper sulfate (copper sulfate pentahydrate; Alpha Chemicals, Cape Girardeau, MO) was added to each carboy to remediate off-aromas that were produced during fermentation. After 11 weeks, the cider was racked into 500-mL polyethylene terephthalate bottles (Great Fermentations, Indianapolis, IN) and stored at $57^{\circ} \mathrm{F}$ for $24 \mathrm{~h}$. The filled bottles were then pressurized and carbonated [55-69 $\mathrm{kPa}$ (Central Welding, Burlington, WA)] at $57^{\circ} \mathrm{F}$ and capped. The finished bottles of cider were stored at $57{ }^{\circ} \mathrm{F}$ for 4 weeks until they were evaluated by a trained panel at WSU in Pullman, WA.

TRAINED PANEL SENSORY EVAluation. A panel of seven males and one female, aged 25-59 years with a mean age of 38 years, participated in $10.5 \mathrm{~h}$ of sensory training over seven evening sessions at the WSU Sensory Evaluation Facility. Panelists were selected based on availability and previous experience on trained sensory panels at WSU School of Food Science. When questioned about the frequency of cider consumption, six of the eight panelists indicated that they consumed the beverage a few times per month and the remaining two panelists consumed the beverage a few times per year. The most commonly consumed brands of cider were Angry Orchard (Boston Beer Co., Boston, MA) and Woodchuck (Vermont Hard Cider Co., Middlebury, VT), both mainstream cider products. This study was approved by the WSU Institutional Review Board, and all participants signed an informed consent form. Panelists received nonmonetary incentives at the completion of each training session and a nonmonetary reward at the completion of the formal evaluations.

Panelists were trained to recognize sensory attributes of cider, assessing samples for color (Petignat-Keller, 2013), aroma (Ballester et al., 2013; Cortell et al., 2008; Noble et al., 1987), flavor (Ballester et al., 2013; Cortell et al., 2008; Noble et al., 1987), mouthfeel (Pickering and Demiglio, 2008), taste (Bleibaum et al., 2002; Pickering and Demiglio, 2008), and aftertaste (Pickering and Demiglio, 2008) (Supplemental Tables 1-3). Industry sensory descriptor wheels were used for the selection of key attributes and modified in response to suggestions by the panelists (Mitchell, 2015; Williams, 2006). A reference standard was prepared to illustrate each attribute, and panelists practiced using these standards at each training session. Attributes providing for continuous data (aroma, flavor, mouthfeel, and taste) were evaluated on a $15-\mathrm{cm}$ line scale, anchored at $\mathbf{1 . 5}$ and $13.5 \mathrm{~cm}$. Attributes providing for categorical data (aftertaste and color) were evaluated along a low, medium, and high scale or a binary detection scale. For formal evaluations, $30 \mathrm{~mL}$ of each cider sample was presented at $68^{\circ} \mathrm{F}$ in a wine glass certified by the Institut National des Appellations d'Origine and the International Organization for Standardization, coded with a three-digit randomized code, and capped with a petri dish to maintain aromas. Each panelist was provided with filtered water and unsalted crackers (Nabisco Premium; Nabisco, East Hanover, NJ) to cleanse the palate during the mandatory $30 \mathrm{~s}$ pause between samples. Samples were presented monadically in a randomized, balanced serving order, and data collected electronically (Compusense Cloud; Compusense, Guelph, ON, Canada). Panelists evaluated 24 ciders (12 samples in duplicate) over three sessions, evaluating a maximum of eight ciders per day to minimize sensory fatigue.

E-TONGUE SENSORY EVALUATION. The $\alpha$-ASTREE II potentiometric e-tongue (Alpha MOS Co., Toulouse, France), located at the WSU Sensory Evaluation Facility, was used to profile cider samples. The e-tongue included a 48-tray liquid automatic sampler system, seven liquid cross-selective taste sensors, a silver/silver chloride $(\mathrm{Ag} / \mathrm{AgCl})$ reference electrode, and chemometrics software (AlphaSoft software version 12; Alpha MOS Co.). The seven sensors detected sweetness, sourness, umami, saltiness, bitterness, metallic, and spiciness. The system measured the potential differences between the sensors' membrane coating and the reference electrode for the cider samples. E-tongue discrimination analysis was conducted to assess the extent to which the e-tongue could distinguish among the samples. Standard conditioning and post-conditioning of the sensors were conducted before sample measurements (Diako et al., 2016). The sensors were hydrated overnight in $25 \mathrm{~mL}$ reagent-grade filtered water (Milli-Q; Merck, Darmstadt, Germany) followed by a confirmatory diagnostic run. A programmed auto sampler method consisting of the following parameters was used: delay $=0 \mathrm{~s}$; acquisition time $=120 \mathrm{~s}$; stirring rate $=1$; and acquisition period $=1$. Before e-tongue analysis, the samples were equilibrated to room temperature and filtered through filter paper (P8 Fisher; Thermo Fisher Scientific). Each cider sample was analyzed in duplicate by the e-tongue; a cleaning step was performed between samples using reagent-grade filtered water (Milli-Q; Merck).

Trained PANel STATISTICAL ANALYSIS. A general linear model was used for the analysis of continuous data; Fisher's least significant difference 
test was carried out to detect differences between the levels of main factors and interactions for significant attributes. A logistical regression model was used for the analysis of categorical data; Fisher's exact test and chi-square test were carried out to determine nonrandom associations between categorical variables. The statistical program used was JMP (version 12.2; SAS Institute, Cary, NC).

E-TONGUE STATISTICAL ANALYSIS. Principal component analysis (PCA) and calculation of discrimination index (DI) were carried out to evaluate the ability of the e-tongue to discriminate among samples. Each sample was represented on a PCA biplot; the closer the plotted duplicates, the less analytical variation for a particular sample in using the e-tongue evaluation method. Discrimination was accomplished by using the DI which gives an indication of the extent of overlapping or distinct surfaces of sample data points projected on the first two principal components. The statistical program used was Astree Alpha Soft (version 12.0; Alpha MOS Co.).

\section{Results and discussion}

Trained panel. For most parameters, main treatment (harvest method, fruit storage time, and year of harvest) effects were nonsignificant $[P>0.05$ (data not shown)]. For all parameters, panelist $(n=8)$ effect was significant $(P<0.001)$, but the interaction of panelist, treatment, and session (formal evaluations completed over three independent days) effects was nonsignificant $[P>0.05$ (data not shown)]. Although panelists are trained to minimize the inherent variation in sensory perception, significant panelist effects are common in sensory research involving complex products such as caviar and wine (Baker et al., 2014; Munoz, 2003). Subsequent results and discussion will focus on significant interaction effects and their practical impact on cider apple growers and cider producers.

In total, three responses of color (brown, orange, and yellow) were evaluated. For the response of brown and orange, samples produced from fruit hand harvested in 2014 on average scored lower (i.e., were perceived as less intense) than samples produced from machine-harvested fruit in 2014 (Table 1). Panelists' response to yellow was inverse to that of their response to brown and orange in terms of harvest method (Table 1). Scoring of the three color responses was similar across 2015 samples for the two harvest methods (Table 1). Overall in 2014, cider samples derived from fruit mechanically harvested were perceived to be darker than cider samples derived from fruit hand harvested, as expected. A significant $(P<0.01)$ interaction of duration of ambient storage time of fruit and year of harvest was observed for the response of orange. On average, the intensity of orange color increased from 0 to 2 weeks storage for 2015 samples, as expected, but perplexingly decreased from 0 to 2 weeks storage for 2014 samples (Table 1). Quantitative measurement of cider color, for example, using the CIELAB color measurement system (Commission internationale de l'éclairage, Vienna, Austria), is recommended for future studies to support panelist results and to allow for a recommendation to cider producers.

In total, 10 responses of aroma (apple, caramel, citrus, earthy, ethanol, floral, grassy, spicy, woody, and yeasty) were evaluated. A significant $(P<$ 0.05 ) interaction of harvest method and year of harvest was observed for the aroma responses of earthy, ethanol, spicy, and woody. For these four aroma responses, samples produced from hand-harvested fruit on average scored lower than samples produced from machine-harvested fruit for the 2014 harvest year, whereas scoring was similar for the two harvest methods in 2015 (Table 2). Greater microbial growth (e.g., Brettanomyces sp.) on the more damaged machineharvested fruit than hand-harvested fruit could explain the differences in aroma attributes such as earthy. The mean values for the four significant aroma responses were on the low end of the scoring scale, suggesting that panelists were able to discriminate among samples at low intensities, and the spread of mean line scale scores was a maximum of $4 \%$ across the levels of all the significant interactions. Use of the reference standards at lower intensities could encourage use of the high end of the scoring scale in future studies. There was a significant $(P<$ 0.05 ) interaction of duration of ambient storage of fruit and year of harvest for the response of earthy. On average, earthy aroma intensified from 2 to 4 weeks storage for the 2014 samples, but intensity remained unchanged through storage for the 2015 samples (Table 2).

In total, nine responses of flavor (apple, caramel, citrus, earthy, floral, grassy, spicy, woody, and yeasty) were evaluated. Flavor is distinct from aroma in that aroma is the sensation perceived when volatile compounds are inhaled through the nose (via the orthonasal pathway), and flavor is a multisense perception involving the inhalation of volatiles through the back of the mouth (via the retronasal pathway). A significant $(P<$ $0.01)$ interaction of the harvest method and year of harvest was observed for earthy, grassy, spicy, woody, and yeasty. For the responses of earthy, grassy, spicy, woody, and yeasty, samples produced from handharvested fruit on average scored lower than samples produced from machine-harvested fruit for the harvest year of 2014, whereas scoring was similar for the two harvest methods in 2015 (Table 3). As with the scoring of aroma attributes, 2014 cider samples derived from machineharvested fruit were perceived to be earthier, grassier, spicier, woodier, and yeastier than 2014 cider samples derived from hand-harvested fruit. These aroma and flavor differences achieved with machine harvest could be advantageous to a cider producer who wants to avoid non-apple inputs and whose consumer base desires these amplified attributes. The mean values for all significant flavor responses were on the low end of the scoring scale. A significant $(P<0.05)$ interaction of duration of ambient storage of fruit and year of harvest was observed for the response of earthy. On average, earthy flavor intensified from 2 to 4 weeks storage for the 2014 samples, similar to earthy aroma, but intensity remained unchanged through storage for the 2015 samples (Table 3 ).

In total, five responses of mouthfeel (astringent, carbonated, creamy, ethanol, and metallic) were evaluated. A significant $(P<0.01)$ interaction of harvest method and year of harvest was observed for astringency, carbonation, and ethanol. For these three responses, samples produced from hand-harvested fruit on average scored lower than samples produced from machine-harvested fruit for the harvest year of 2014, whereas scoring 
Table 1. Mean line scale scores for the three assessed color attributes across the levels of the significant harvest method and year of harvest interaction and the significant duration of ambient [mean of $56^{\circ} \mathrm{F}\left(13.3^{\circ} \mathrm{C}\right)$ ] storage of fruit and year of harvest interaction, used by the eight trained panelists in evaluating apple cider samples on a $15-\mathrm{cm}$ scale.

\begin{tabular}{lccc}
\hline & Brown $(\mathbf{c m})^{\mathrm{z}}$ & Orange $(\mathrm{cm})$ & Yellow $(\mathbf{c m})$ \\
\hline $\begin{array}{l}\text { Harvest method } \times \text { yr } \\
\text { Hand } \times 2014\end{array}$ & $5.95 \mathrm{~b}^{\mathrm{y}}$ & $4.64 \mathrm{c}$ & \\
Machine $\times 2014$ & $6.91 \mathrm{a}$ & $6.89 \mathrm{a}$ & $9.00 \mathrm{a}$ \\
Hand $\times 2015$ & $6.78 \mathrm{a}$ & $5.90 \mathrm{~b}$ & $7.11 \mathrm{~b}$ \\
Machine $\times 2015$ & $6.53 \mathrm{ab}$ & $5.88 \mathrm{~b}$ & $7.66 \mathrm{~b}$ \\
Storage $\times$ yr & & & $8.28 \mathrm{ab}$ \\
0 weeks $\times 2014$ & 6.38 & $6.30 \mathrm{ab}$ & 8.17 \\
2 weeks $\times 2014$ & 6.89 & $5.79 \mathrm{abc}$ & 7.95 \\
4 weeks $\times 2014$ & 6.02 & $5.19 \mathrm{bc}$ & 8.05 \\
0 weeks $\times 2015$ & 6.24 & $4.93 \mathrm{c}$ & 8.28 \\
2 weeks $\times 2015$ & 6.96 & $6.49 \mathrm{a}$ & 7.54 \\
4 weeks $\times 2015$ & 6.77 & $6.25 \mathrm{ab}$ & 8.08 \\
\hline
\end{tabular}

${ }^{\mathrm{z}} 1 \mathrm{~cm}=0.3937$ inch.

${ }^{y}$ Different letters in a given column indicate significant differences $(P<0.05)$ in the scoring of an attribute among the levels of the specific interaction (harvest method $\times$ year or storage $\times$ year) listed on the $y$-axis, as determined by Fisher's least significant difference test.

Table 2. Mean line scale scores for the four assessed aroma attributes across the levels of the significant harvest method and year of harvest interaction and the significant duration of ambient [mean of $56^{\circ} \mathrm{F}\left(13.3^{\circ} \mathrm{C}\right)$ ] storage of fruit and year of harvest interaction, used by the eight trained panelists in evaluating apple cider samples on a $15-\mathrm{cm}$ scale.

\begin{tabular}{ccccc}
\hline & Earthy $(\mathbf{c m})^{\mathbf{z}}$ & Ethanol $(\mathbf{c m})$ & Spicy $(\mathbf{c m})$ & Woody $(\mathbf{c m})$ \\
\hline Harvest method $\times$ yr & & & & \\
Hand $\times 2014$ & $1.19 \mathrm{~b}^{\mathrm{y}}$ & $3.90 \mathrm{~b}$ & $2.30 \mathrm{~b}$ & $2.20 \mathrm{~b}$ \\
Machine $\times 2014$ & $1.70 \mathrm{a}$ & $4.70 \mathrm{a}$ & $2.93 \mathrm{a}$ & $2.86 \mathrm{a}$ \\
Hand $\times 2015$ & $1.66 \mathrm{ab}$ & $4.66 \mathrm{a}$ & $2.60 \mathrm{ab}$ & $2.79 \mathrm{a}$ \\
Machine $\times 2015$ & $1.40 \mathrm{ab}$ & $4.60 \mathrm{a}$ & $2.39 \mathrm{ab}$ & $2.55 \mathrm{ab}$ \\
Storage $\times$ yr & & & & \\
0 weeks $\times 2014$ & $1.26 \mathrm{~b}$ & 4.18 & 2.53 & 2.88 \\
2 weeks $\times 2014$ & $1.16 \mathrm{~b}$ & 4.55 & 2.83 & 2.39 \\
4 weeks $\times 2014$ & $1.92 \mathrm{a}$ & 4.16 & 2.48 & 2.81 \\
0 weeks $\times 2015$ & $1.56 \mathrm{ab}$ & 4.79 & 2.64 & 2.40 \\
2 weeks $\times 2015$ & $1.59 \mathrm{ab}$ & 4.72 & 2.48 & 2.97 \\
4 weeks $\times 2015$ & $1.43 \mathrm{ab}$ & 4.78 & 2.55 & 2.64 \\
\hline
\end{tabular}

${ }^{\mathrm{z}} 1 \mathrm{~cm}=0.3937$ inch.

${ }^{\mathrm{y}}$ Different letters in a given column indicate significant differences $(P<0.05)$ in the scoring of an attribute among the levels of the specific interaction (harvest method $\times$ year or storage $\times$ year) listed on the $y$-axis, as determined by Fisher's least significant difference test.

was similar for the two harvest methods in 2015 (Table 4). For the year 2014, cider samples derived from mechanically harvested fruit were perceived to be more astringent, carbonated, and heated than cider samples derived from hand-harvested fruit. The greater astringency of the machine-harvested samples than the hand-harvested samples was opposite of our expectation. However, the result is not necessarily in conflict with the original hypothesis of an altered phenolic content resulting in lesser astringency, as acidity has been demonstrated to affect panelists' perception recommended for minimizing variation within treatments in future studies, for providing consumers with a consistent product and ensuring compliance with tax code (Alcohol and Tobacco Tax and Trade Bureau, 2015).

In total, three responses of taste (bitter, sour, and sweet) were evaluated. A significant $(P<0.01)$ interaction of the harvest method and year of harvest was observed for the responses of bitter and sour. For the responses of bitter and sour, samples produced from hand-harvested fruit on average scored lower than samples produced from machineharvested fruit for the harvest year of 2014, whereas scoring was similar for the two harvest methods in 2015 (Table 4). For the year 2014, cider samples derived from mechanically harvested fruit were perceived to be more bitter and sour than cider samples derived from hand-harvested fruit. The greater perceived sourness of the 2014 machine-harvested samples than the 2014 hand-harvested samples indicates a greater acidity for the machine-harvested samples and could explain the astringency result discussed previously.

In total, five responses of aftertaste (duration, apple, astringent, metallic, and sweet) were evaluated. Variation due to the main effect of the year of harvest was shown to be significant $(P<0.01)$ for the response of sweet. The likelihood of sweetness not being detected as an aftertaste was significantly higher for cider samples in 2014 than 2015 (data not shown). A significant $(P<0.05)$ interaction of duration of ambient storage of fruit and harvest method was shown for the response of metallic. The likelihood of panelists detecting a metallic aftertaste decreased for machine-harvested samples from 0 weeks storage to 2 weeks storage, whereas likelihoods of detection were similar for handharvested fruit (data not shown). The frequencies of zero detection for all significant attributes were greater than $80 \%$.

Overall, the trained panelists on average scored the 2014 cider samples sourced from machine-harvested fruit compared with hand-harvested fruit as follows: darker in color; having earthier, spicier, and woodier aromatic and flavor profiles; a more astringent, carbonated, and heated mouthfeel; and a more bitter and sour 
Table 3. Mean line scale scores for the five assessed flavor attributes across the levels of the significant harvest method and year of harvest interaction and the significant duration of ambient [ mean of $56{ }^{\circ} \mathrm{F}\left(13.3{ }^{\circ} \mathrm{C}\right)$ ] storage of fruit and year of harvest interaction, used by the eight trained panelists in evaluating apple cider samples on a $15-\mathrm{cm}$ scale.

\begin{tabular}{|c|c|c|c|c|c|}
\hline & Earthy $(\mathrm{cm})^{\mathrm{z}}$ & Grassy $(\mathrm{cm})$ & Spicy $(\mathrm{cm})$ & Woody $(\mathrm{cm})$ & Yeasty $(\mathrm{cm})$ \\
\hline \multicolumn{6}{|l|}{ Harvest method $\times$ yr } \\
\hline Hand $\times 2014$ & $1.08 \mathrm{~b}^{\mathrm{y}}$ & $2.11 \mathrm{~b}$ & $2.33 \mathrm{c}$ & $2.65 \mathrm{~b}$ & $2.56 \mathrm{~b}$ \\
\hline Machine $\times 2014$ & $1.88 \mathrm{a}$ & $2.78 \mathrm{a}$ & $3.27 \mathrm{a}$ & $3.63 \mathrm{a}$ & $3.47 \mathrm{a}$ \\
\hline Hand $\times 2015$ & $1.89 \mathrm{a}$ & $2.90 \mathrm{a}$ & $2.89 \mathrm{ab}$ & $3.53 \mathrm{a}$ & $3.46 \mathrm{a}$ \\
\hline Machine $\times 2015$ & $1.85 \mathrm{a}$ & $2.49 \mathrm{ab}$ & $2.78 \mathrm{bc}$ & $3.44 \mathrm{a}$ & $3.38 \mathrm{a}$ \\
\hline \multicolumn{6}{|l|}{ Storage $\times$ yr } \\
\hline 4 weeks $\times 2014$ & $1.92 \mathrm{a}$ & 2.64 & 2.87 & 3.26 & 3.00 \\
\hline 0 weeks $\times 2015$ & $1.57 \mathrm{ab}$ & 2.52 & 3.01 & 3.12 & 3.43 \\
\hline 2 weeks $\times 2015$ & $1.59 \mathrm{ab}$ & 2.87 & 3.06 & 3.34 & 3.45 \\
\hline 4 weeks $\times 2015$ & $1.43 \mathrm{ab}$ & 2.69 & 2.72 & 3.20 & 3.39 \\
\hline
\end{tabular}

${ }^{\mathrm{z}} 1 \mathrm{~cm}=0.3937$ inch.

${ }^{y}$ Different letters in a given column indicate significant differences $(P<0.05)$ in the scoring of an attribute among the levels of the specific interaction $($ harvest method $\times$ year or storage $\times$ year) listed on the $y$-axis, as determined by Fisher's least significant difference test.

Table 4. Mean line scale scores for the three assessed mouthfeel attributes and two taste attributes across the levels of the significant harvest method and year of harvest interaction, used by the eight trained panelists in evaluating apple cider samples on a $15-\mathrm{cm}$ scale.

\begin{tabular}{|c|c|c|c|c|c|}
\hline Harvest method $\times$ yr & Astringent $(\mathrm{cm})^{\mathrm{z}}$ & Carbonated $(\mathrm{cm})$ & Ethanol $(\mathrm{cm})$ & Bitter $(\mathrm{cm})$ & Sour $(\mathrm{cm})$ \\
\hline Machine $\times 2014$ & $7.20 \mathrm{a}$ & $2.92 \mathrm{a}$ & $4.88 \mathrm{a}$ & $5.22 \mathrm{a}$ & $6.32 \mathrm{a}$ \\
\hline Machine $\times 2015$ & $7.33 \mathrm{a}$ & $2.97 \mathrm{a}$ & $4.56 \mathrm{a}$ & $4.98 \mathrm{a}$ & $6.42 \mathrm{a}$ \\
\hline
\end{tabular}

${ }^{\mathrm{z}} 1 \mathrm{~cm}=0.3937$ inch.

${ }^{y}$ Different letters in a given column indicate significant differences $(P<0.05)$ in the scoring of an attribute among the levels of the specific interaction $($ harvest method $\times$ year $)$ listed on the $y$-axis, as determined by Fisher's least significant difference test.

taste. These same distinctions were not made among 2015 samples, as panelists did not detect any significant variation due to harvest method for any of the sensory attributes. Although panelist effect was consistently significant, the panelists' profiling of the varietal cider assessed in this study as a whole aligned with previous evaluations by expert cider makers (Zimmerman et al., 2016).

E-Tongue. For the ciders prepared in 2014, the first two components of the PCA described $90 \%$ of the variation observed among the cider samples (Fig. 1). The 2014 samples exhibited good separation with a DI of 95. The closer a sample was located to a particular sensor vector, the more that sensor could be used to describe that particular sample. The 2014 cider samples derived from hand-harvested fruit as a whole were best described by their responses to the bitter, sweet, and umami sensors. In terms of duration of ambient storage of fruit, the ciders sourced from hand-harvested fruit that were ambient stored for 0 weeks (coded as H14T0Rlor2) were best described by their response to sweet and bitter; those ambient stored for 2 weeks (coded as H14T2Rlor2) were best described by their response to spicy and umami; and those ambient stored for 4 weeks (coded as H14T4Rlor2) were best described by their response to spicy and salty. The ciders sourced from mechanically harvested fruit as a whole were best described by their responses to the metallic and sour sensors. In terms of duration of ambient storage of fruit, the ciders sourced from machineharvested fruit that were ambient stored for 0 and 2 weeks (coded as M14T0Rlor2 and M14T2Rlor2) were best described by their response to metallic, and those ambient stored for 4 weeks (coded as Ml4T4Rlor2) were best described by their response to sour.

For the ciders prepared in 2015 , the first two components of the PCA described 91\% of the variation observed among the cider samples (Fig. 2). The 2015 samples exhibited little separation with a DI of -0.5 . The
2015 cider samples derived from hand-harvested fruit as a whole were best described by their responses to the bitter, sweet, and umami sensors. In terms of duration of ambient storage of fruit, the ciders sourced from hand-harvested fruit that were ambient stored for 0 weeks (coded as H15T0Rlor2) were best described by their response to bitter, and those ambient stored for 4 weeks (coded as M15T4Rlor2) were best described by their response to sweet and umami. The ciders sourced from mechanically harvested fruit as a whole were best described by their responses to the metallic and sour sensors. In terms of duration of ambient storage of fruit, the ciders sourced from machineharvested fruit that were ambient stored for 0 weeks (coded as M15T0Rlor2) were best described by their response to sweet, and those ambient stored for 2 weeks (coded as M15T2Rlor2) were best described by their response to metallic and sour.

Overall, a distinct separation between machine- and hand-harvested ciders was observed for the e-tongue 


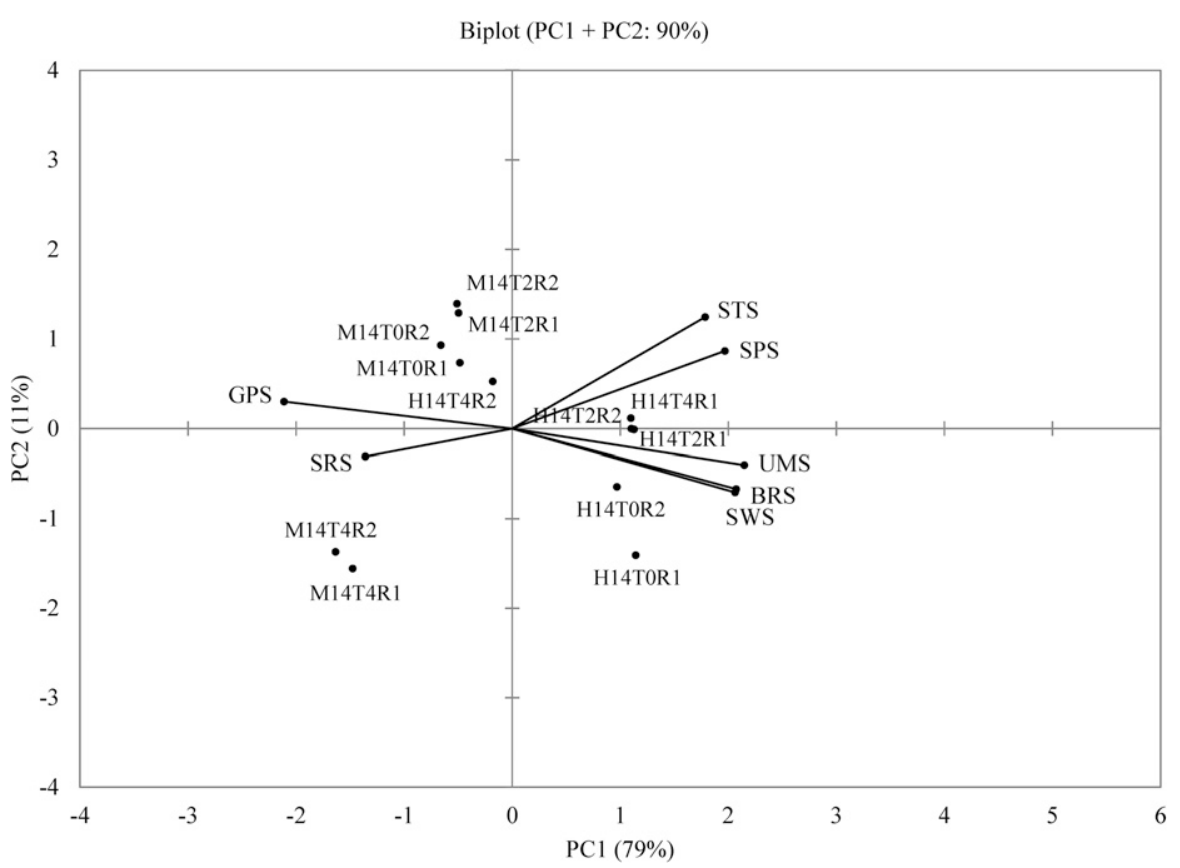

Fig. 1. Principal component analysis (PCA) biplot demonstrating electronic tongue separation [using seven sensors: bitter (BRS), metallic (GPS), salty (STS), sour (SRS), spicy (SPS), sweet (SWS), and umami (UMS)] of apple cider samples produced from 2014 hand- or machine-harvested fruit (coded as $\mathrm{H}$ or $\mathrm{M}$ ) that were ambient [mean of $56^{\circ} \mathrm{F}\left(13.3^{\circ} \mathrm{C}\right)$ ] stored for 0,2 , or 4 weeks postharvest (coded as T0, T2, and T4); H14T0R1 represents a cider sample produced from fruit hand harvested in 2014 and ambient stored for 0 weeks postharvest, replicate one of two.

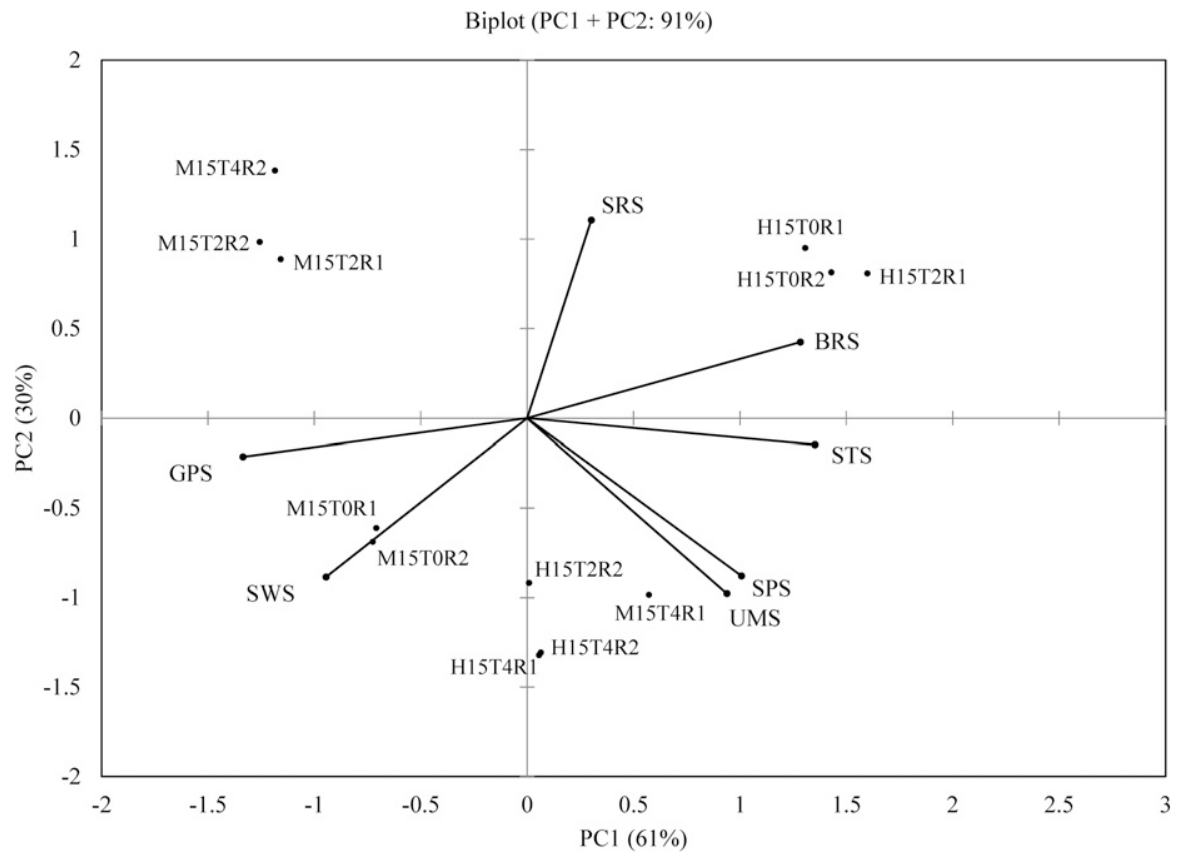

Fig. 2. Principal component analysis (PCA) biplot demonstrating electronic tongue separation [using seven sensors: bitter (BRS), metallic (GPS), salty (STS), sour (SRS), spicy (SPS), sweet (SWS), and umami (UMS)] of apple cider samples produced from 2015 hand- or machine-harvested fruit (coded as $\mathrm{H}$ or $\mathrm{M}$ ) that were ambient [mean of $56^{\circ} \mathrm{F}\left(13.3^{\circ} \mathrm{C}\right)$ ] stored for 0,2 , or 4 weeks postharvest (coded as T0, T2, and T4); M15T4R2 represents a cider sample produced from fruit machine harvested in 2015 and ambient stored for 4 weeks postharvest, replicate two of two. with the exception of two unexplainable outliers, M15T4Rl and H14T4R2. A response to the bitter, sweet, and umami sensors were more associated with the hand-harvested samples and a response to the metallic and sour sensors were associated with the machine-harvested samples. The e-tongue differentiated machine- and hand-harvested samples identically to the trained panelists in terms of the attributes of metallic and sour, and inversely to the trained panelists in terms of the attribute of bitter. The e-tongue's response to bitterness was in line with our expectation, the handharvested samples were more bitter than the machine-harvested samples. The metallic response associated with the machine-harvested samples mirrors findings with machine-harvested grapes; however, it is important to note that the fruit contact surfaces of the harvester used in this study were predominantly fiberglass or plastic based. Also, the fruit had relatively short contact time with any surface of the harvester as fruit were immediately (in less than $60 \mathrm{~s}$ ) transferred to plastic grape boxes. The application of copper sulfate post-fermentation could have also contributed to the metallic response, as discussed by Hudelson (2011). Furthermore, untargeted application of copper sulfate could have impacted the sensory results differentially as copper sulfate has been shown to remove universally disliked odors such as rotten eggs and beverage characteristic aromas such as passion fruit in Sauvignon blancs (Coetzee and du Toit, 2012; Harbertson, 2009). Not using copper sulfate in the production process would be ideal as it can affect the sensory character of different samples in different ways. Steps should be taken to prevent the formation of hydrogen sulfide during fermentation, thus making the addition of copper sulfate unnecessary and avoiding this potentially significant source of added sensory variation (i.e., sensory variation not attributable to the experimental treatments). Cider apple growers and cider producers should use metalbased contact surfaces and processing aids with caution (e.g., conducting copper sulfate fining trials rather than applying standard aliquots) given the potential impacts on cider clarity and taste. 
Different harvest crews for the hand-harvest treatment in 2014 and 2015 resulted in a significantly greater percent bruising of hand-harvested fruit in $2015(78 \%)$ than 2014 (15\%; Alexander et al., 2016). This difference in level of bruising of hand-harvested fruit could have accounted for the year-to-year variation in trained panelist and e-tongue results. Given that the percent of hand-harvested fruit bruised in 2014 was representative of what would be observed in commercial practice with a more experienced harvest crew, the perceived sensory differences demonstrated in 2014 are expected and the lack of differences in 2015 unlikely. For example, cider producers should expect a greater level of earthy aromas with machine-harvested fruit than hand-harvested fruit as demonstrated with the 2014 samples. Whereas the trained panelists demonstrated conflicting results for the duration of ambient storage treatments from 2014 to 2015 , the e-tongue demonstrated the development of attributes over storage time, as expected.

\section{Conclusions}

Reducing human labor input in cider apple production would provide cider apple growers with a more stable and decreased cost of operation. Utilization of an over-the-row shake-andcatch machine harvester is one such strategy for reducing labor input. Whereas machine-harvest of 'Brown Snout' has been demonstrated to provide for similar yields and juice quality characteristics to hand-harvest, in this study, the sensory profiles of varietal ciders derived from machine- and hand-harvested 'Brown Snout' were shown to be different in one of the 2 years studied. Both the trained panelists and an e-tongue perceived machine-harvested samples to be more metallic and sour than handharvested samples. Conducting a consumer tasting panel is recommended as the next step in evaluating cider quality as it would provide cider producers with an indication of market response to the differing sensory profiles. If market response is generally favorable, then cider apple growers can seriously consider harvesting their fruit using over-therow shake-and-catch technology that is economically feasible for their operation (Tennant, 2017). Given the yield loss results from ambient storage of machine-harvested 'Brown Snout'
(Alexander et al., 2016) for more than 0 weeks and the variable sensory results demonstrated in this study, cider apple growers should not ambient store machine-harvested cider apples for any period of time. Furthermore, provided that fruit are consistently machineharvested at full maturity and with the same equipment, crew, and protocol year-to-year, cider apple growers should expect to be able to supply cider producers with a raw material of consistent quality. Finally, as the used e-tongue did not strongly complement the human evaluations, further development is needed before the e-tongue can become a recommended component of cider sensory evaluation.

\section{Literature cited}

Alcohol and Tobacco Tax and Trade Bureau. 2015. Code of federal regulations, 27 CFR Part 24. 17 Mar. 2016. <https:// www.ttb.gov/other/regulations.shtml>.

Alcohol and Tobacco Tax and Trade Bureau. 2017. Cider statistics CY 20072016. U.S. Dept. Treasury, Washington, DC.

Alexander, T.R., J. King, E. Scheenstra, and C.A. Miles. 2016. Yield, fruit damage, yield loss and juice quality characteristics of machine and hand-harvested 'Brown Snout' specialty cider apple stored at ambient conditions in northwest Washington. HortTechnology 26:614-619.

Baker, A.K., B. Vixie, B.A. Rasco, M. Ovissipour, and C.F. Ross. 2014. Development of a lexicon for caviar and its usefulness for determining consumer preference. J. Food Sci. 79:S2533S2541

Baldwin, E.A., J. Bai, A. Plotto, and S. Dea. 2011. Electronic noses and tongues: Applications for the food and pharmaceutical industries. Sensors (Basel) 11:4744-4766.

Ballester, J., M. Mihnea, D. Peyron, and D. Valentin. 2013. Exploring minerality of Burgundy Chardonnay wines: A sensory approach with wine experts and trained panelists. Austral. J. Grape Wine Res. 19:140-152.

Blanpied, G.D. and K.J. Silsby. 1992. Predicting harvest date windows for apples. Cornell Coop. Ext. Publ. Info. Bul. 221.

Bleibaum, R.N., H. Stone, T. Tan, S. Labreche, E. Saint-Martin, and S. Isz. 2002. Comparison of sensory and consumer results with electronic nose and tongue sensors for apple juices. Food Qual. Prefer. 13:409-422.
Chu, C.L.G. and K.R. Wilson. 2000. Evaluating maturity of 'McIntosh' and 'Red Delicious' apples. Ontario Ministry Agr. Food Rural Affairs Publ. Order No. 00025. 3 May 2016. <http://www.omafra. gov.on.ca/english/crops/facts/00-025. htm>.

Coetzee, C. and W.J. du Toit. 2012. A comprehensive review on Sauvignon Blanc aroma with a focus on certain positive volatile thiols. Food Res. Intl. 45:287-298.

Cortell, J.M., H.K. Sivertsen, J.A. Kennedy, and H. Heymann. 2008. Influence of vine vigor on Pinot Noir fruit composition, wine chemical analysis, and wine sensory attributes. Amer. J. Enol. Viticult. 59:1-10.

deMan, J.M. 1999. Principles of food chemistry. 3rd ed. Springer-Verlag, Berlin, Germany.

Diako, C., K. McMahon, S. Mattinson, M. Evans, and C.F. Ross. 2016. Alcohol, tannins, and mannoprotein and their interactions influence the sensory properties of selected commercial Merlot wines: A preliminary study. J. Food Sci. 81:S2039S2048.

Fontoin, H., C. Saucier, P-L. Teissedre, and Y. Glories. 2008. Effect of pH, ethanol and acidity on astringency and bitterness of grape seed tannin oligomers in model wine solution. Food Qual. Prefer. 19:286-291.

Guyot, S., S. Bernillon, P. Poupard, and C.M. Renard. 2008. Multiplicity of phenolic oxydation products in apple juices and ciders, from synthetic medium to commercial products, p. 278-292. In: F. Daayf and V. Lattanzio (eds.). Recent advances in polyphenol research. WileyBlackwell, Oxford, UK.

Harbertson, J.F. 2009. A guide to the fining of wine. Washington State Univ. Ext. Publ. EM016.

Hudelson, J. 2011. Wine faults: Causes, effects, cures. Board and Bench Publ., San Francisco, CA.

Lea, A. 1990. Bitterness and astringency: The procyanidins of fermented apple ciders, p. 123-143. In: R.L. Rousseff (ed.). Bitterness in foods and beverages. Elsevier, Oxford, UK.

Lea, A. and G.M. Arnold. 1978. The phenolics of cider: Bitterness and astringency. J. Sci. Food Agr. 29:478-483.

Legin, A., A. Rudnitskaya, L. Lvova, Y. Vlasov, C. Di Natale, and A.A. D'Amico. 2003. Evaluation of Italian wine by the electronic tongue: Recognition, quantitative analysis and correlation with human sensory perception. Anal. Chim. Acta 484:33-44. 
Loubère, L.A. 1990. The wine revolution in France: The twentieth century. Princeton Univ. Press, Princeton, NJ.

Meilgaard, M.C., B.T. Carr, and G.V. Civille. 2006. Sensory evaluation techniques. 4th ed. CRC Press, Boca Raton, FL.

Miles, C.A. and J. King. 2014. Yield, labor, and fruit and juice quality characteristics of machine and hand-harvested 'Brown Snout' specialty cider apple. HortTechnology 24:519-526.

Mitchell, P. 2015. Cider \& perry production: Principles \& practice course notes. Mitchell F\&D, Newent, UK.

Moulton, G.A. and J. King. 2008. Fruit handbook for western Washington. Washington State Univ. Ext. Publ. EB0937.

Munoz, A. 2003. Training time in descriptive analysis, p. 351-356. In: H.R. Moskowitz, A.M. Munoz, and M.C. Gacula (eds.). Viewpoints and controversies in sensory science and consumer product testing. Food Nutrition Press, Trumbull, CT.

Nicolas, J.J., F.C. Richard-Forget, P.M. Goupy, M.J. Amiot, and S.Y. Aubert. 1994. Enzymatic browning reactions in apple and apple products. Crit. Rev. Food Sci. Nutr. 34:109-157.

Noble, A.C., R.A. Arnold, J. Buechsenstein, E.J. Leach, J.O. Schmidt, and P.M. Stern. 1987. Modification of a standardized system of wine aroma terminology. Amer. J. Enol. Viticult. 38:143-146.

Petignat-Keller, S. 2013. Flavour wheel for apple juice and cider. Agroscope Changins-Wädenswil Res. Sta., Wädenswil, Switzerland.

Pickering, G. and P. Demiglio. 2008. The white wine mouthfeel wheel: A lexicon for describing the oral sensations elicited by white wine. J. Wine Res. 19:51-67.

Renard, C.M., A. Baron, S. Guyot, and J-F. Drilleau. 2001. Interactions between apple cell walls and native apple polyphenols: Quantification and some consequences. Intl. J. Biol. Macromol. 29:115-125.

Tennant, H. 2017. Costs and considerations for establishing cider apple orchards for mechanical harvest. MS Rpt., Washington State Univ., Pullman, WA.

Thilmany, D.D. 2001. Farm labor trends and management in Washington State. J. Agribusiness 19:1-15.
U.S. Department of Agriculture. 2013. Web soil survey. 3 May 2017. <http:// websoilsurvey.sc.egov.usda.gov.html>.

Washington State University. 2013. Crop protection guide for tree fruits in Washington. Washington State Univ. Ext. Publ. EB0419.

Williams, A.A. 2006. The development of a vocabulary and profile assessment method for evaluating the flavour contribution of cider and perry aroma constituents. J. Sci. Food Agr. 26:567-582.

Zimmerman, A., J. King, E. Scheenstra, and C.A. Miles. 2016. Evaluation of varietal ciders produced at WSU Mount Vernon NWREC. 26 July 2017. <http://cider. wsu.edu/wp-content/uploads/sites/54/ 2017/05/CiderEvaluations2016.pdf>.

Zimmerman, A., G. Moulton, and C.A. Miles. 2015. Fermentation protocol at WSU Mount Vernon NWREC for production of varietal ciders. 3 May 2017. <http://extl00.wsu.edu/maritimefruit/ wp-content/uploads/sites/36/2015/ 04/CiderFermentationProtocol2015. pdf>. 
Supplemental Table 1. Color attributes (principal and secondary terms), reference standards, and reference intensities [low $(\mathrm{L})$, medium $(\mathrm{M})$, and high $(\mathrm{H})]$ used by the eight trained panelists in evaluating cider apple samples on a 15 -cm line scale.

\begin{tabular}{|c|c|c|c|}
\hline$\underline{\text { Principal term }}$ & Secondary term & Standard $^{\mathrm{z}}$ & Intensity $(\mathrm{cm})^{\mathrm{y}}$ \\
\hline \multirow[t]{3}{*}{ Color } & Brown & L: Valspar Mellow Moment (VR040D) & L: 2.5 \\
\hline & & M: Valspar Montana Wheat Field (VR040C) & M: 7 \\
\hline & & H: Valspar Sweet Mulled Cider (VR040A) & $\mathrm{H}: 12.5$ \\
\hline \multirow[t]{3}{*}{ Color } & Orange & L: Clark + Kensington Make Me Laugh $\left(12 \mathrm{~B}-3^{\mathrm{U}}\right)$ & $\mathrm{L}: 2.5$ \\
\hline & & M: Clark + Kensington Sun Goes Down $\left(12 B-4^{M}\right)$ & M: 7 \\
\hline & & $\mathrm{H}$ : Clark + Kensington Glazed Peach $\left(12 \mathrm{~B}-5^{\mathrm{M}}\right)$ & $\mathrm{H}: 11$ \\
\hline Color & & H: Valspar Bonjour (VR012B) & $\mathrm{H}: 12.5$ \\
\hline
\end{tabular}

${ }^{\mathrm{z}}$ Paint swatches (Valspar, Minneapolis, MN).

${ }^{\mathrm{y}} 1 \mathrm{~cm}=0.3937$ inch.

Supplemental Table 2. Aroma, flavor, mouthfeel, and taste attributes (principal and secondary terms), reference standards, base solutions of reference standards, and reference intensities used by the eight trained panelists in evaluating apple cider samples on a $15-\mathrm{cm}$ line scale.

\begin{tabular}{|c|c|c|c|c|}
\hline Principal term & Secondary term & Standard $^{\mathrm{z}}$ & Base solution $^{\mathrm{y}}$ & Intensity $(\mathrm{cm})^{\mathrm{z}}$ \\
\hline Burnt & Caramel & 35 g caramelized sugar & $\mathrm{CHC}$ & 10 \\
\hline Chemical & Ethanol & $15 \mathrm{~mL} 950 \mathrm{~g} \cdot \mathrm{kg}^{-1}$ ethanol & $\mathrm{CHC}$ & 9 \\
\hline Floral & Rose & Three drops 2-phenylethanol & $\mathrm{CHC}$ & 10 \\
\hline Fruity & Apple & Chopped 1/2 'Granny Smith' apple & $\mathrm{CHC}$ & 10 \\
\hline Fruity & Citrus & $1 / 2$ grapefruit (Citrus $\times$ paradisi) & $\mathrm{CHC}$ & 9.5 \\
\hline Spicy & Clove & 10 cloves (Syzygium aromaticum) & $\mathrm{CHC}$ & 11 \\
\hline Woody & Oaky & 12 oak (Quercus alba) chips soaked overnight & $\mathrm{CHC}$ & 9.5 \\
\hline Principal term & Secondary term & Standard & Base solution & Intensity $(\mathrm{cm})$ \\
\hline Burnt & Caramel & 35 g caramelized sugar & $\mathrm{CHC}$ & 9 \\
\hline Earthy & Earthy & $20 \mathrm{~g}$ potting soil & $\mathrm{CHC}$ & 11 \\
\hline Microbiological & Yeasty & One tbsp active dry yeast & $\mathrm{CHC}$ & 10.5 \\
\hline Spicy & Clove & 10 whole cloves & $\mathrm{CHC}$ & 10.5 \\
\hline Woody & Oaky & 12 oak chips soaked overnight & $\mathrm{CHC}$ & 9.5 \\
\hline Principal term & Secondary term & Standard ${ }^{\mathrm{x}}$ & Base solution & Intensity $(\mathrm{cm})$ \\
\hline Drying & Astringent & $0.10 \mathrm{~g}$ alum sulfate & $\mathrm{CHC}$ & 9 \\
\hline Prickly & Carbonated & $20 \mathrm{~mL}$ mineral water & None & 10 \\
\hline Mouth coating & Creamy & Refer to definition & None & Low/High \\
\hline Heat & Ethanol & $35 \mathrm{~mL}$ ethanol & $\mathrm{H}_{2} \mathrm{O}$ & 10 \\
\hline Metallic & Metallic & Six ground iron tablets & $\mathrm{CHC}$ & 9.5 \\
\hline Principal term & Secondary term & Standard ${ }^{\mathrm{w}}$ & Base solution & Intensity $(\mathrm{cm})$ \\
\hline Bitter & Bitter & $0.025 \mathrm{~g}$ quinine sulfate & AJ & 11 \\
\hline
\end{tabular}

${ }^{\mathrm{z}}$ Active dry yeast (Red Star Yeast Co., Milwaukee, WI), whole cloves (McCormick \& Co., Sparks, MD), fresh fruit (Safeway, Pullman, WA), sucrose (California and Hawaiian Sugar Co., Crockett, CA), ethanol, hexanal, and 2-phenlyethanol (Sigma-Aldrich, St. Louis, MO), potting soil (Scotts Miracle-Gro, Marysville, OH), oak chips (Gusmer Enterprises, Mountainside, NJ); $1 \mathrm{~cm}=0.3937$ inch, $1 \mathrm{~g}=0.0353 \mathrm{oz}, 1 \mathrm{~mL}=0.0338 \mathrm{fl} \mathrm{oz}, 1 \mathrm{~g} \cdot \mathrm{kg}^{-1}=0.0160 \mathrm{oz} / \mathrm{lb}, 1 \mathrm{drop}=0.05 \mathrm{~mL}$, and $\mathrm{l}$ tablespoon $(\mathrm{tbsp})=14.7868 \mathrm{~g}$. ${ }^{\mathrm{y}} \mathrm{CHC}=$ base solution of $250 \mathrm{~mL}$ commercial cider (Crisp Apple; Boston Beer Co.), $\mathrm{H}_{2} \mathrm{O}=$ base solution of $250 \mathrm{~mL}$ filtered water (EcoLab, St. Paul, MN), AJ = base solution of $250 \mathrm{~mL}$ apple juice (Tree Top, Prosser, WA).

${ }^{\mathrm{x}}$ Alum sulfate (McCormick \& Co.), mineral water (Perrier, Vergèze, France), and iron tablets (Nature Made, Northridge, CA).

${ }^{\text {w }}$ Quinine sulfate (Sigma-Aldrich) and malic acid (Brewcraft, Vancouver, WA). 


\section{Research Reports}

Supplemental Table 3. Aftertaste attributes used by the eight trained panelists in evaluating apple cider samples on a ordinal and binary scale.

\begin{tabular}{ll}
\hline Principal term & \multicolumn{1}{c}{ Definition } \\
\hline Duration & Length taste lasts in the mouth \\
& Low: $0-20 \mathrm{~s}$ \\
& Medium: $20-40 \mathrm{~s}$ \\
& High: $40-60+\mathrm{s}$ \\
Detection & Detection $(0=$ no, $1=$ yes $)$ of descriptors, \\
& as defined previously, after spitting out the sample \\
${ }^{\mathrm{z}}$ Descriptors detected for apple, astringent, & metallic, and sweet.
\end{tabular}

